\title{
Relationship Between Smoking and Structural Damage, Autoimmune Antibodies, and Disability in Rheumatoid Arthritis Patients
}

\author{
Filiz SİVAS, ${ }^{1}$ Fatma Gül YURDAKUL, ${ }^{1}$ Ayşegül KILIÇARSLAN, ${ }^{1}$ \\ Semra DURAN, ${ }^{2}$ Bedriye BAŞKAN, ${ }^{1}$ Hatice BODUR ${ }^{1}$ \\ ${ }^{1}$ Department of Physical Medicine and Rehabilitation, Ankara Numune Training and Research Hospital, Ankara, Turkey \\ ${ }^{2}$ Department of Radiology, Ankara Numune Training and Research Hospital, Ankara, Turkey
}

\begin{abstract}
Objectives: This study aims to investigate the relationship between smoking and structural damage, autoimmune antibodies, and disability in rheumatoid arthritis (RA) patients.

Patients and methods: This cross-sectional study included 165 RA patients ( 36 males, 129 females; mean age $52.4 \pm 12.8$ years; range 21 to 82 years). Disease duration, age at disease onset, smoking habits, rheumatoid factor (RF), and anti-cyclic citrullinated peptide levels were recorded. Morning stiffness, pain with visual analog scale, Health Assessment Questionnaire Scores And Disease Activity Score 28 were calculated. Patients' standard hand radiographs were evaluated.

Results: Patients were divided into three groups according to their smoking habits. Ninety-nine patients (60\%) were never smokers, 45 patients (27.3\%) were long-term smokers and 21 patients (12.7\%) were new smokers. Three groups were compared for disease activity. Disease activity score 28 scores were $3.2 \pm 1.2,3.2 \pm 1.3$, and $3.2 \pm 1.4$, respectively ( $p>0.05$ ). The erosion score $(2.6 \pm 5.8,7.1 \pm 10.9$, and $11.1 \pm 19.2$, respectively) and joint space narrowing score $(9.9 \pm 7.3,18.6 \pm 14.9$, and $17.3 \pm 12.3$, respectively) according to modified Sharp method were significantly lower in never smokers group than other groups ( $\mathrm{p}<0.05$ ). RF titrations were $55.2 \pm 58.9,60.5 \pm 63.1$, and $84.9 \pm 71.5$, respectively, and levels of long-term smokers group were significantly higher than the other groups $(p<0.05)$. Joint space narrowing score was $16.2 \pm 11.9$ and $6.4 \pm 10.4$ in RF $(+)$ and RF $(-)$ patients, respectively $(p<0.05)$. There was no significant relationship between anti-cyclic citrullinated peptide levels and others parameters.

Conclusion: Although smoking is known as a poor prognostic factor in RA, there was no correlation between disease activity and smoking in our study. However, less radiographic damage was found in never smokers. Smoking does not appear to correlate with RA disease activity but it may be effective in the long-term joint damage.

Keywords: Autoimmune antibodies; pulmonary involvement; rheumatoid arthritis; smoking; structural damage.
\end{abstract}

Rheumatoid arthritis (RA) is a common inflammatory rheumatic disease, affecting about $1 \%$ of all people worldwide and the most important outcome of RA being joint destruction and functional disability.1,2 Interaction between environmental factors and genetic and immune systems are held responsible for the development of joint damage. ${ }^{3}$ It has been shown that smoking, which is an environmental risk factor for RA, modulates the immune system and is effective on the development of RA and some autoimmune disorders. $^{3-6}$ Autoimmune antibodies such as rheumatoid factor (RF) and anti-cyclic citrullinated peptide (anti-CCP) have prognostic significance for the development of RA.?

Relationship between smoking and production of RF and anti-CCP has been reported. ${ }^{8} \mathrm{RF}$ positivity is found in $70-80 \%$ of patients with $\mathrm{RA}^{9}$ and frequency of RF positivity was shown to be higher in smokers in the general population and long-term smokers among patients with RA. ${ }^{10,11}$ On the other hand, smoking can also increase the risk of RA development by triggering the immune response to citrullinated protein antigens. ${ }^{6}$ 
While RA may have a quite heterogeneous course ranging between mild to severe disease, the mechanisms affecting this course are not known clearly. Smoking has been indicated as a poor prognostic factor in RA by immunopathologic mechanisms, hormonal pathways or direct toxic effects. ${ }^{12}$ There are studies with conflicting results that determined a relationship between smoking and disease activity, radiologic progression and response to treatment., ${ }^{4,8,13}$ In our knowledge, no study has been conducted with Turkish RA patients investigating the relationship between smoking and joint damage, disease activity and disability. Therefore, in this study, we aimed to investigate the relationship between smoking and structural damage, autoimmune antibodies, and disability in RA patients.

\section{PATIENTS AND METHODS}

One hundred and sixty-five RA patients (36 males, 129 females; mean age 52.4 12.8 years; range 21 to 82 years) followed in Ankara Numune Training and Research Hospital between January 2015 and February 2016, who fulfilled the 1987 American College of Rheumatology criteria and 2010 American College of Rheumatology/European League Against Rheumatism RA classification criteria were included in this cross-sectional study. ${ }^{14,15}$ The study protocol was approved by the Ankara Numune Training and Research Hospital Ethics Committee. A written informed consent was obtained from each patient. The study was conducted in accordance with the principles of the Declaration of Helsinki. Patients younger than 18 years and older than 85 years, with severe cognitive problems, active cancer in their history, severe organ failure or severe neurologic diseases (i.e. multiple sclerosis, amyotrophic lateral sclerosis, stroke or spinal cord disorders) were excluded.

Age, sex and body mass index of all patients were recorded. Disease duration, age at disease onset and the drugs used were questioned. Drug use was recorded as (i) synthetic disease modifier antirheumatic drugs (DMARDs), (ii) biologic DMARDs and (iii) not receiving DMARD therapy.

Patients were classified according to their smoking habits as never smokers, long-term smokers (smoking for longer than two years) and new smokers (smoking for two years or less). Patients were also grouped according to the number of packs they smoked as never smokers, smokers of one to nine packs per year, 10 to 19 packs per year and $\geq 20$ packs per year (heavy smokers).

Clinical variables including duration of morning stiffness, tender and swollen joint counts, pain scores measured with visual analog scale $(0-10 \mathrm{~cm})$, patient and physician global disease assessments were recorded. Disease activity score 28 with erythrocyte sedimentation rate was calculated. Functional status was assessed with health assessment questionnaire. ${ }^{16,17}$

Whole blood count and routine biochemical tests were carried out for all patients. Erythrocyte sedimentation rate levels were determined using the quantitative capillary photometry principle. $\mathrm{RF}$ (positive if patient had a value $>14 \mathrm{IU} / \mathrm{L}$ ) and $\mathrm{C}$-reactive protein levels were tested with immunoturbidimetric method. Anti-CCP measurement was carried out using the Abbott AxSYM System Digoxin III Reagent Pack (Abbott Laboratories, Abbott Park, IL, USA) with enzyme linked fluorescent assay, and values $>5 \mathrm{U} / \mathrm{mL}$ were accepted as positive.

Of 165 patients, X-rays of both hands and wrists of 127 were viewed. Joint damage was assessed by the same radiologist. Seventeen erosion scores (ESs) and joint space narrowing (JSN) score at 18 areas were evaluated using the modified Sharp method. ${ }^{2,18}$

All patients were examined for pulmonary involvement and the relationship with smoking was analyzed. Patients were evaluated by a thoracic diseases specialist and were followed-up with physical examination, lung $\mathrm{X}$-rays and computed tomography where needed according to the recommendations of the specialist.

\section{Statistical analysis}

IBM SPSS for Windows version 20.0 (IBM Corp., Armonk, NY, USA) package program was used for statistical analyses. Shapiro-Wilk test was used to test for normality; the results of this test indicated that parametric and nonparametric tests should be performed. The general descriptive statistics for continuous 
variables were summarized as the mean, median and standard deviation values. When analyzing the differences of the continuous variables between two groups, the t-test for two independent groups was used for data with normal distribution, and Mann-Whitney $U$ test was used for data without normal distribution. The homogeneity of the distributions of categorical variables was determined using Chi-square or Fisher's exact tests. The variables were compared between the patients subdivided into three groups according to the smoking status using one-way analysis of variance. Post-hoc tests (Bonferroni) were used to establish differences between groups. The threshold for statistical significance was set at $\mathrm{p}<0.05$.

\section{RESULTS}

Demographic data and clinical characteristics of patients are shown in Table 1. Current treatments were as follows: 117 patients were using synthetic DMARDs, 28 patients were using biologic DMARDs, and 20 patients were not receiving DMARD therapy (they were using corticosteroids and/or non-steroidal anti-inflammatory drugs).

According to smoking habits, there were 99 never smokers (60\%), 45 long-term smokers (27.3\%) and 21 new smokers (12.7\%). The mean age was lower in new smokers and the percentage of male patients was higher in long-term smokers. RF titration was higher in long-term smokers compared to new smokers and never smokers.

\begin{tabular}{lccc}
\hline Table 1. Clinical features of patients $(\mathrm{n}=165)$ & & \\
\hline Characteristics of the patients & Mean \pm SD & Median & Min-Max \\
\hline Age (year) & $52.4 \pm 12.8$ & & \\
Body mass index $\left(\mathrm{kg} / \mathrm{m}^{2}\right)$ & & 27.64 & $14.86-49.78$ \\
Disease duration $(\mathrm{month})$ & 120 & $24-480$ \\
Erythrocyte sedimentation rate $(\mathrm{mm} / \mathrm{h})$ & 18 & $2-90$ \\
C-reactive protein $(\mathrm{mg} / \mathrm{dL})$ & 6.10 & $0.17-72.72$ \\
Tender joint count & $9.5 \pm 13.1$ & & \\
Swollen joint count & $0.8 \pm 2.4$ & 5 & $0-300$ \\
Morning stiffness $(\mathrm{Sc})$ & & 3 & $0-10$ \\
Visual analog scale-pain $(0-10 \mathrm{~cm})$ & & 3.08 & $0.49-0655$ \\
Disease activity score 28 & & 0.87 & $0.00-2.87$ \\
Health assessment questionnaire & & & \\
\hline SD: Standard deviation. & & & \\
\hline
\end{tabular}

Table 2. Clinical and laboratory data in relation to smoking status

\begin{tabular}{|c|c|c|c|c|c|c|c|}
\hline & \multicolumn{2}{|c|}{ Never smoker $(n=99)$} & \multicolumn{2}{|c|}{ New smoker $(n=21)$} & \multicolumn{2}{|c|}{ Long-term smoker $(n=45)$} & \multirow[b]{2}{*}{$p$} \\
\hline & $\mathrm{n}$ & Mean \pm SD & $\mathrm{n}$ & Mean \pm SD & $\mathrm{n}$ & Mean \pm SD & \\
\hline Age (year) & & $54.6 \pm 3.0$ & & $44.9 \pm 3.0$ & & $53.0 \pm 2.24$ & $<0.05^{*}, \dagger, \S$ \\
\hline Disease duration (month) & & $156.3 \pm 69.0$ & & $132.0 \pm 101.5$ & & $114.3 \pm 101.0$ & $>0.05$ \\
\hline Age at disease onset (year) & & $40.3 \pm 12.1$ & & $33.9 \pm 12.9$ & & $45.1 \pm 9.1$ & $>0.05$ \\
\hline Sex & & & & & & & $<0.05^{*}$ \\
\hline Female & 89 & & 17 & & 23 & & \\
\hline Male & 10 & & 4 & & 22 & & \\
\hline Rheumatoid factor & & $55.6 \pm 58.9$ & & $60.5 \pm 63.1$ & & $84.9 \pm 71.5$ & $<0.05^{*}, \neq, \S$ \\
\hline Anti-cyclic citrullinated peptide & & $203.9 \pm 336.4$ & & $320.3 \pm 655.3$ & & $362.8 \pm 534.3$ & $>0.05$ \\
\hline Tender joint count & & $8.9 \pm 12.6$ & & $9.7 \pm 13.4$ & & $10.4 \pm 14.1$ & $>0.05$ \\
\hline Swollen joint count & & $0.7 \pm 2.7$ & & $1.0 \pm 2.0$ & & $0.7 \pm 1.7$ & $>0.05$ \\
\hline Disease activity score 28 & & $3.6 \pm 1.4$ & & $3.2 \pm 1.4$ & & $3.2 \pm 1.3$ & $>0.05$ \\
\hline Visual analog scale & & $3.6 \pm 2.8$ & & $3.3 \pm 2.7$ & & $4.3 \pm 2.8$ & $>0.05$ \\
\hline Erythrocyte sedimentation rate & & $22.0 \pm 14.9$ & & $20.6 \pm 15.4$ & & $18.1 \pm 11.9$ & $>0.05$ \\
\hline C-reactive protein & & $10.9 \pm 13.3$ & & $10.4 \pm 15.1$ & & $10.4 \pm 12.4$ & $>0.05$ \\
\hline Health assessment questionnaire & & $1.0 \pm 0.9$ & & $1.1 \pm 0.8$ & & $0.9 \pm 0.8$ & $>0.05$ \\
\hline Joint space narrowing & & $9.9 \pm 7.3$ & & $17.3 \pm 12.3$ & & $18.6 \pm 14.9$ & $<0.05^{*}$, †キ \\
\hline Erosion score & & $2.6 \pm 5.4$ & & $11.1 \pm 19.2$ & & $7.1 \pm 10.9$ & $<0.05^{*}, t, \ddagger$ \\
\hline
\end{tabular}


Table 3. Relationship between amounts of smoking (pack-years) and rheumatoid factor and anti-cyclic citrullinated peptide levels

\begin{tabular}{|c|c|c|c|c|c|}
\hline & $\begin{array}{c}\text { Never smoker } \\
(\mathrm{n}=99)\end{array}$ & $\begin{array}{c}\text { 1-9 package-year } \\
(\mathrm{n}=27)\end{array}$ & $\begin{array}{c}\text { 10-19 package-year } \\
(\mathrm{n}=11)\end{array}$ & $\begin{array}{c}\geq 20 \text { pack-year } \\
(\mathrm{n}=28)\end{array}$ & \\
\hline & Mean \pm SD & Mean \pm SD & Mean \pm SD & Mean \pm SD & $p$ \\
\hline Rheumatoid factor & $55.2 \pm 58.9$ & $57.4 \pm 64.5$ & $49.4 \pm 40.5$ & $107.1 \pm 73.5$ & $<0.05^{*}$ \\
\hline Anti-cyclic citrullinated peptide & $320.7 \pm 655.3$ & $262.8 \pm 473.7$ & $251.5 \pm 261.2$ & $536.7 \pm 777.5$ & $>0.05$ \\
\hline
\end{tabular}

JSN and ES values were significantly lower in never smokers group compared to other groups $(p<0.05)$. No statistically significant differences were found between the disease duration, visual analog scale pain score, tender joint count, swollen joint count, erythrocyte sedimentation rate, C-reactive protein level, disease activity score 28 and health assessment questionnaire scores in three smoking groups (Table 2).

The relationship between the amount of smoking (pack-year) with RF and anti-CCP titrations was studied. RF titration was higher in heavy smoker group ( $\geq 20$ pack-year) compared to other groups (Table 3).

Relationship between smoking and radiologic damage, RF, and anti-CCP levels was examined. While there was no relationship between RF positivity and ESs ( $p>0.05)$, significant relationship was found with JSN score (Table 4).

Rheumatoid lung disease was found in 40 out of 165 patients. Parenchymal involvement was detected in 35 patients (21.2\%), pleural involvement in one patient $(0.6 \%)$, and pleuralparenchymal involvement in four patients (2.4\%). No significant differences were found between lung involvement groups as regards to smoking, $\mathrm{RF} /$ anti-CCP positivity, JSN, and disease activity score 28 values. Mean disease duration was longer and ESs were higher in patients with pulmonary involvement (Table 5).

\section{DISCUSSION}

In this study, our aim was to investigate the relationship between smoking and joint damage,

Table 4. Relationship between smoking and autoantibody levels and joint damage

\begin{tabular}{lccccc}
\hline & \multicolumn{2}{c}{ JSN } & & ES & \\
\cline { 2 - 4 } & Mean \pm SD & $p$ & Mean \pm SD & $p$ \\
\hline Rheumatoid factor (+) patients & $16.3 \pm 11.9$ & $<0.05^{*}$ & $6.3 \pm 10.4$ & $>0.05$ \\
Rheumatoid factor (-) patients & $12.8 \pm 11.8$ & & $6.1 \pm 13.9$ & \\
Anti-cyclic citrullinated peptide (+) patients & $15.8 \pm 11.8$ & $>0.05$ & $5.9 \pm 10.4$ & $>0.05$ \\
Anti-cyclic citrullinated peptide (-) patients & $14.1 \pm 12.3$ & & $7.2 \pm 13.8$ & \\
\hline JSN: Joint space narrowing; ES: Erosion score; SD: Standard deviation. & & & \\
\hline
\end{tabular}

Table 5. Pulmonary involvement and clinical variables

\begin{tabular}{|c|c|c|c|c|c|c|c|}
\hline & \multicolumn{3}{|c|}{ Pulmonary involvement $(-)(\mathrm{n}=125)$} & \multicolumn{3}{|c|}{ Pulmonary involvement $(+)(n=40)$} & \multirow[b]{2}{*}{$p$} \\
\hline & $\mathrm{n}$ & $\%$ & Mean \pm SD & $\mathrm{n}$ & $\%$ & Mean \pm SD & \\
\hline Never smoker & 73 & 73.7 & & 26 & 26.3 & & \\
\hline New smoker & 15 & 71.4 & & 6 & 28.6 & & 0.48 \\
\hline Long-term smoker & 37 & 82.2 & & 8 & 17.8 & & \\
\hline Rheumatoid factor $(+)$ patients & 89 & 71.2 & & 32 & 80.0 & & 0.27 \\
\hline Anti-cyclic citrullinated peptide $(+)$ patients & 92 & 73.6 & & 31 & 77.5 & & 0.68 \\
\hline Disease activity score 28 & & & $3.2 \pm 1.4$ & & & $3.1 \pm 1.4$ & 0.45 \\
\hline Disease duration & & & $128.1 \pm 98.2$ & & & $174 \pm 82.2$ & $<0.01^{*}$ \\
\hline Joint space narrowing & & & $13.9 \pm 10.9$ & & & $19.1 \pm 13.6$ & 0.06 \\
\hline Erosion score & & & $4.6 \pm 8.5$ & & & $10.7 \pm 16.0$ & $0.02^{*}$ \\
\hline
\end{tabular}


autoimmune antibodies, disease activity, disability and pulmonary involvement in patients with established RA. Our results support that more progressive joint damage and higher RF titrations were associated with long-term smoking. However, smoking, disease activity, disability, and anti-CCP levels seem to be unrelated.

Smoking is an important factor that may increase the oxidative stress and trigger inflammation in RA. ${ }^{6,19,20}$ Effects of smoking on disease activity, damage progression and relationship with autoimmune antibodies were investigated several times; however, contradictory results were obtained from studies. . $^{3-5,7,8,13,19,21,22}$ It has been reported that $\mathrm{RA}$ incidence, production of RF and anti-CCP increase in smokers. ${ }^{7,23}$ In a multicenter study, significant relationship was found between smoking and RF titrations in patients with RA. ${ }^{24}$ Manfredsdottir et al. ${ }^{12}$ showed that immunoglobulin A RF levels were higher in former and current smokers compared to never smokers. Despite these findings, Saevarsdottir et al. ${ }^{13}$ and Tareo et al. ${ }^{22}$ reported no significant association between smoking and autoantibodies. But then, Tareo et al. ${ }^{22}$ detected significant dosedependent effect of smoking on high levels of RF and anti-CCP in general population. In our study, while the association between RF titration and smoking was significant, there was no relationship between anti-CCP levels and smoking. RF titration was significantly higher in the long-term smokers as compared to the new and never smokers. RF titration was also higher in heavy smokers compared to other groups. Our results indicate an association between smoking and RF titrations similar to the literature. Anti-CCP levels that did not have any relationship may also be affected by various mechanisms and immune pathways.

The relationship between smoking and disease activity and functional disability attracts clinicians' attention. There are numerous studies showing that smoking aggravates disease activity, $8,12,13$ but there are also studies with conflicting results. Papadopoulos et al. ${ }^{4}$ identified a significant relationship between the disease activity parameters and smoking in patients with early RA. Masdottir et al. ${ }^{23}$ showed that disease activity was more severe in heavy smokers than never or less smokers with RA. On the other hand, there was no relationship between smoking and disease activity and severity in Krol et al. ${ }^{7}$ and
Naranjo et al.'s studies. ${ }^{24}$ Furthermore, Harrison et al. ${ }^{25}$ investigated functional disability in smoker RA patients and found no relationship between health assessment questionnaire score and smoking. In our study, there was no relationship between smoking and both disease activity and functional disability. It is known that there are several parameters affecting disease activity and functional disability in RA. The results of our study demonstrated that sex distribution and mean age were not homogeneous in the never smoker, new and long-term smoker groups. Also, treatment protocols, steroid and biological DMARD use were dissimilar in the groups. Mentioned differences may have influenced our results. It may be more useful to work with more homogeneous groups in terms of treatment and demographic characteristics, while assessing the relationship between smoking, disease activity and functional disability in RA.

Studies investigating the relationship between smoking and joint damage in RA have produced different results. While significant relationship was reported between smoking and radiologic damage in patients with $\mathrm{RA}, 4,23,26,27$ no relationship was determined in other studies. ${ }^{7,8,23,25}$ Saag et al. ${ }^{26}$ found significant relationship between smoking and radiologic damage particularly in RF (+) patients with RA. In our established RA patients, radiologic joint damage scores were significantly lower in the never smoker group compared to the other smoker groups as many previous studies. The remarkable point in our results was that disease duration was similar in the three smoking groups. We did not find any relationship between smoking and radiologic damage and anti-CCP antibodies, while there was significant relationship between smoking and RF. Although it is common belief that the effects of smoking are apparent through anti-CCP, ${ }^{28}$ some authors argued that anti-CCP antibodies were not a marker of severity in established RA. ${ }^{29}$ Anti-CCP and $\mathrm{RF}$ can play a triggering role in the onset of erosive disease; however, autoantibodies may not be as effective on the more active and severe course of established RA. The absence of an association between anti-CCP and smoking may be due to the fact that our patients had established RA.

Diagnosis of interstitial pulmonary disease in RA is important since it can be related with 
the natural course of the disease. Gochuico et al. ${ }^{30}$ found interstitial pulmonary disease in 33\% of asymptomatic RA patients without cough or dyspnea. They reported that smoking or methotrexate may be a risk factor for pulmonary disease. Moreover, Kawassaki et al. ${ }^{31}$ investigated pulmonary disease in patients with RA and found that lung involvement was related to smoking. In our study, lung involvement was determined in 40 patients out of 165 (24.2\%). Our results indicated that disease duration was longer in patients with lung involvement, although lung involvement groups were similar in terms of age and sex distribution. However, we did not find any significant relationship between lung involvement and disease activity, smoking, anti$\mathrm{CCP}$ and RF levels. Rheumatoid lung disease may be associated with disease duration rather than smoking. Further detailed studies with larger sample size are needed on this issue. Although no relationship was found in this study between smoking and lung disease, patients were advised to quit smoking.

The limitation of our study was that the number and characteristics of the RA patients were not homogeneous in the smoker groups. Since this was a cross-sectional study, new smoker group coincided with a small number of patients. The homogeneity of the numbers of patients in the smoker groups, and inclusion of several parameters such as passive smoking could affect the results of analysis. Therefore, longterm studies with larger samples are required to validate the results.

In conclusion, we showed a significant association between smoking and RF titration but not with anti-CCP levels. However, we did not determine any relationship between smoking and disease activity and functional disability. Smoking seems to be a factor that increases joint damage. Although anti-CCP can play a triggering role particularly in early arthritis, there may be additional components that affect disease activity, functional disability and joint damage in established RA.

\section{Declaration of conflicting interests}

The authors declared no conflicts of interest with respect to the authorship and/or publication of this article.

\section{Funding}

The authors received no financial support for the research and/or authorship of this article.

\section{REFERENCES}

1. Tasliyurt T, Kisacik B, Kaya SU, Yildirim B, Pehlivan Y, Kutluturk F, et al. The frequency of antibodies against cyclic citrullinated peptides and rheumatoid factor in healthy population: a field study of rheumatoid arthritis from northern Turkey. Rheumatol Int 2013;33:939-42.

2. Sivas F, Barça N, Onder M, Ozoran K. The relation between joint erosion and generalized osteoporosis and disease activity in patients with rheumatoid arthritis. Rheumatol Int 2006;26:896-9.

3. Sugiyama D, Nishimura K, Tamaki K, Tsuji G, Nakazawa T, Morinobu A, et al. Impact of smoking as a risk factor for developing rheumatoid arthritis: a meta-analysis of observational studies. Ann Rheum Dis 2010;69:70-81.

4. Papadopoulos NG, Alamanos Y, Voulgari PV, Epagelis EK, Tsifetaki N, Drosos AA. Does cigarette smoking influence disease expression, activity and severity in early rheumatoid arthritis patients? Clin Exp Rheumatol 2005;23:861-6.

5. Bang SY, Lee KH, Cho SK, Lee HS, Lee KW, Bae SC. Smoking increases rheumatoid arthritis susceptibility in individuals carrying the HLA-DRB1 shared epitope, regardless of rheumatoid factor or anti-cyclic citrullinated peptide antibody status. Arthritis Rheum 2010;62:369-77.

6. Di Giuseppe D, Discacciati A, Orsini N, Wolk A. Cigarette smoking and risk of rheumatoid arthritis: a dose-response meta-analysis. Arthritis Res Ther 2014;16:61.

7. Krol A, Garred P, Heegaard NH, Christensen AF, Hetland ML, Stengaard-Pedersen K, et al. Interactions between smoking, increased serum levels of antiCCP antibodies, rheumatoid factors, and erosive joint disease in patients with early, untreated rheumatoid arthritis. Scand J Rheumatol 2015;44:8-12.

8. Westhoff G, Rau R, Zink A. Rheumatoid arthritis patients who smoke have a higher need for DMARDs and feel worse, but they do not have more joint damage than non-smokers of the same serological group. Rheumatology (Oxford) 2008;47:849-54.

9. Serdaroğlu M, Cakirbay H, Değer O, Cengiz S, Kul S. The association of anti-CCP antibodies with disease activity in rheumatoid arthritis. Rheumatol Int 2008;28:965-70.

10. Halldórsdóttir HD, Jónsson $\mathrm{T}$, Thorsteinsson $\mathrm{J}$, Valdimarsson $\mathrm{H}$. A prospective study on the incidence of rheumatoid arthritis among people with persistent increase of rheumatoid factor. Ann Rheum Dis 2000;59:149-51. 
11. Jónsson T, Thorsteinsson J, Valdimarsson H. Does smoking stimulate rheumatoid factor production in non-rheumatic individuals? APMIS 1998;106:970-4.

12. Manfredsdottir VF, Vikingsdottir $\mathrm{T}$, Jonsson $\mathrm{T}$, Geirsson AJ, Kjartansson O, Heimisdottir M, et al. The effects of tobacco smoking and rheumatoid factor seropositivity on disease activity and joint damage in early rheumatoid arthritis. Rheumatology (Oxford) 2006;45:734-40.

13. Saevarsdottir S, Rezaei H, Geborek P, Petersson I, Ernestam S, Albertsson K, et al. Current smoking status is a strong predictor of radiographic progression in early rheumatoid arthritis: results from the SWEFOT trial. Ann Rheum Dis 2015;74:1509-14.

14. Arnett FC, Edworthy SM, Bloch DA, McShane DJ, Fries JF, Cooper NS, et al. The American Rheumatism Association 1987 revised criteria for the classification of rheumatoid arthritis. Arthritis Rheum 1988;31:315-24.

15. Smolen JS, Landewé R, Breedveld FC, Dougados M, Emery P, Gaujoux-Viala C, et al. EULAR recommendations for the management of rheumatoid arthritis with synthetic and biological diseasemodifying antirheumatic drugs. Ann Rheum Dis 2010;69:964-75.

16. Skogh T, Gustafsson D, Kjellberg M, Husberg M. Twenty eight joint count disease activity score in recent onset rheumatoid arthritis using $\mathrm{C}$ reactive protein instead of erythrocyte sedimentation rate. Ann Rheum Dis 2003;62:681-2.

17. Küçükdeveci AA, Sahin $H$, Ataman S, Griffiths $\mathrm{B}$, Tennant A. Issues in cross-cultural validity: example from the adaptation, reliability, and validity testing of a Turkish version of the Stanford Health Assessment Questionnaire. Arthritis Rheum 2004;51:14-9.

18. Sharp JT, Wolfe F, Mitchell DM, Bloch DA. The progression of erosion and joint space narrowing scores in rheumatoid arthritis during the first twentyfive years of disease. Arthritis Rheum 1991;34:660-8.

19. Jiang X, Alfredsson L, Klareskog L, Bengtsson C. Smokeless tobacco (moist snuff) use and the risk of developing rheumatoid arthritis: results from a case-control study. Arthritis Care Res (Hoboken) 2014;66:1582-6.

20. Kalpakcioglu B, Senel K. The interrelation of glutathione reductase, catalase, glutathione peroxidase, superoxide dismutase, and glucose-6phosphate in the pathogenesis of rheumatoid arthritis. Clin Rheumatol 2008;27:141-5.
21. Stolt P, Bengtsson C, Nordmark B, Lindblad S, Lundberg I, Klareskog L, et al. Quantification of the influence of cigarette smoking on rheumatoid arthritis: results from a population based casecontrol study, using incident cases. Ann Rheum Dis 2003;62:835-41.

22. Terao C, Ohmura K, Ikari K, Kawaguchi T, Takahashi M, Setoh K, et al. Effects of smoking and shared epitope on the production of anti-citrullinated peptide antibody in a Japanese adult population. Arthritis Care Res (Hoboken) 2014;66:1818-27.

23. Masdottir B, Jónsson T, Manfredsdottir V, Víkingsson A, Brekkan A, Valdimarsson H. Smoking, rheumatoid factor isotypes and severity of rheumatoid arthritis. Rheumatology (Oxford) 2000;39:1202-5.

24. Naranjo A, Toloza S, Guimaraes da Silveira I, Lazovskis J, Hetland ML, Hamoud H, et al. Smokers and non smokers with rheumatoid arthritis have similar clinical status: data from the multinational QUEST-RA database. Clin Exp Rheumatol 2010;28:820-7.

25. Harrison BJ, Silman AJ, Wiles NJ, Scott DG, Symmons DP. The association of cigarette smoking with disease outcome in patients with early inflammatory polyarthritis. Arthritis Rheum 2001;44:323-30.

26. Saag KG, Cerhan JR, Kolluri S, Ohashi K, Hunninghake GW, Schwartz DA. Cigarette smoking and rheumatoid arthritis severity. Ann Rheum Dis 1997;56:463-9.

27. Mattey DL, Hutchinson D, Dawes PT, Nixon NB, Clarke S, Fisher J, et al. Smoking and disease severity in rheumatoid arthritis: association with polymorphism at the glutathione S-transferase M1 locus. Arthritis Rheum 2002;46:640-6.

28. Chang K, Yang SM, Kim SH, Han KH, Park SJ, Shin JI. Smoking and rheumatoid arthritis. Int $\mathrm{J}$ Mol Sci 2014;15:22279-95.

29. Porto LS, Tavares Júnior WC, Costa DA, Lanna CC, Kakehasi AM. Anti-CCP antibodies are not a marker of severity in established rheumatoid arthritis: a magnetic resonance imaging study. Rev Bras Reumatol 2017;57:15-22.

30. Gochuico BR, Avila NA, Chow CK, Novero LJ, Wu $\mathrm{HP}$, Ren $\mathrm{P}$, et al. Progressive preclinical interstitial lung disease in rheumatoid arthritis. Arch Intern Med 2008;168:159-66.

31. Kawassaki AM, Pereira DA, Kay FU, Laurindo IM, Carvalho CR, Kairalla RA. Pulmonary involvement in rheumatoid arthritis: evaluation by radiography and spirometry. J Bras Pneumol 2015;41:331-42. 